There are multiple ways to approach this book. In addition to simply reading it in the conventional fashion, a reader can meaningfully navigate via graphics. With so many rich maps and illustrations that are stories in and of themselves, one can move sequentially through these and search out the textual content that is relevant to each. In fact, I repeatedly approached the book in exactly this manner. Still another method is to seek out the main characters and case studies in the book, to appreciate the in-depth scholarship the author demonstrates and the scope of the material covered.

The content of this book will be of interest to those in a variety of academic disciplines. To me, it seems particularly well-suited to historians and geographers-especially those with cultural, economic, and industrial interests. In addition, anthropologists, sociologists, and even art and literature historians will find the scope of material to be of interest.

There is so much to admire in Mastering Iron that any criticism is certain to seem petty. If a subsequent edition of this book is written, I would offer a pair of suggestions based entirely on my own approach and experience. First, I would welcome an introductory section to serve as a "layperson's guide to iron-making." The glossary, which appears at the end of the book, is helpful; however, an early survey of the technology and key developments in iron-making (perhaps including a timeline) would be of great benefit. There is an immensely helpful section in Chapter 5 that explains the puddling, boiling, and Bessemer processes in production. Many readers would likely appreciate having these and other related processes explained at the beginning of the book, to increase their understanding throughout.
A second suggestion relates to the maps and is as much an observation as a suggestion. There appears to be a variety of symbol design schemes among the different maps. For example, Figure 63 is a map showing Confederate ironworks and Union territorial gains, 1861-65. This map uses symbols of distinct shapes and hues to distinguish different types of ironworks. Figure 14 is a map showing furnaces and deposits of iron ore and coal, using only hue to distinguish between different types of furnaces. Figure 17 shows sources of semifinished iron and iron ore for rolling mills, ca. 1854-58. This map uses yet another combination, with sizes and hues to distinguish between different iron sources. Whether these different symbol designs are intentional, I do not know. While each map is clearly explained and well designed, in my opinion the overall work would benefit from greater consistency in the use of symbols.

A unique pair of figures are found in Chapter $1 \mathrm{~F}$ that warrant special mention. Each combine a map and a graph to show patterns of construction of blast furnaces (Figure 9) and rolling mills (Figure 11) both geographically and also over time. The author notes the inspiration for these figures being the idea of a musical score. I found both the idea and the execution of these figures to be of compelling interest.

In summary, Mastering Iron: The Struggle to Modernize an American Industry, 1800-1868 is a wonderfully written and produced book. I give it my highest recommendation for anyone with even the slightest interest in the history of the US iron-making industry. I look forward to future work by this author.

\title{
LAKE EFFECT: TALES OF LARGE LAKES, ARCTIC WINDS, AND RECURRENT
}

SNOWS

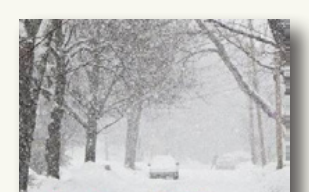

Lake Effect

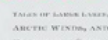

II ark Monmonier

By Mark Monmonier.

Syracuse University Press, 2012.

246 pages. \$24.95, Hardcover

ISBN: 978-0-8156-1004-5

Review by: Bob Hickey, Central

Washington University
As a long-time fan, I was looking forward to reading Mark Monmonier's Lake Effect: Tales of Large Lakes, Arctic Winds, and Recurrent Snows. It was particularly relevant, as I started reading the book in February at Chicago's O'Hare Airport-hoping for an uneventful flight west.

Over the years, I've read a number of Mark's books, going so far as to require How to Lie With Maps in my introductory cartography classes (Mark, if you're reading this, an updated version would be greatly appreciated!). Lake 
Effect, like the others, was written for a public audience and is highly accessible.

When we think of weather in the US, there are three primary mechanisms: orographic precipitation in the West, frontal precipitation in the Plains and East, and the occasional hurricane. However, in the areas immediately to the east/southeast of the Great Lakes, there's another mechanism: lake effect snows. These are caused by cold northerly winds blowing across the Great Lakes which pick up (and dump) additional moisture. Snowfall can be significant, though often very localized. As such, they haven't received much attention outside the impacted areas.

Lake Effect is laid out in seven chapters, taking the reader from a discussion of what is lake effect snow through the mapping, forecasting, impacts, and long-term changes.

Chapter One comprises a quick description of lake effect snow and where it occurs.

Chapter Two is very much a cartographic history of the understanding of lake effect snows. It includes a brief history of (northeast US) meteorology. Interestingly, it wasn't until the 1960s that reasonably accurate maps of lake effect snow were available.

Chapter Three, like the previous two, takes a historical perspective-this time of weather forecasting in the region. A 1921 article by Mitchell and Day gave "perhaps the most concise, scientific explanation of lake effect snow" (60). However, any sort of prediction had to wait until the 1940s and the invention of radar. Even so, decent predictions required satellite imagery, a better understanding of physics, better ground radar coverage, and computers for the complex calculations. As of the writing of this book (2012), lake effect snow forecasting was still not as good as it could be. The resolution is $5 \mathrm{~km}$, not good enough to accurately capture something as local as lake effect snow. Honestly, the description of the quality of forecasting was a surprise-I expect the Weather Channel to be spot on, especially in the short term.
Chapter Four starts with a discussion of how snowfall is measured-there are far more complications with this than one would initially think. It then goes on to discuss the impacts of considerable snow falling in a short period, focusing on different types of transportation: horse, rail, car, pedestrian.

Chapter Five is about local bragging rights. In other words, snowfall records (and some of the impacts of these record snows). Interestingly, there are two local awards given annually: The Golden Snowball to the city in Upstate New York (Buffalo, Syracuse, Rochester, Binghamton, Albany) with the highest annual snowfall and the Silver Snowball, an award started in 2004 which includes many smaller towns.

Chapter Six looks at long-term trends in lake effect snowfall. Over the past century, there appears to be a slight trend toward more snow; there are also links to the ENSO cycle. The chapter finishes with a nod toward global warming and a simple prediction: warmer temperatures will result in less snow.

Chapter Seven wraps things up with a proper geographical sense of place. This is then tied to a bit of a sales pitch for the region (four distinct seasons, winter recreation, etc). Clearly the author enjoys living in Syracuse!

Overall, this book is well written and gives a solid overview of the history and impacts of lake effect snow. As mentioned, it's written for the mass market, so there is considerable overlap between the chapters (repetition, repetition, repetition - a hallmark of teaching). Don't look for in-depth analyses of the weather/climate/physics/modeling etc.- that would quickly lose the intended audience.

That said, this book is a must-read for anyone interested in weather/climate. It details a unique (to the US, anyway) weather mechanism. I would also recommend it to anyone living near the Great Lakes-it will put the snowy life you live into perspective. As someone who fits into both groups (interested in weather and a former resident of the region), I found the book to be both entertaining and informative. 